\title{
Comparing Theories to Explain Exercise Behaviour: A Socio-Cognitive Approach
}

\section{Author 1, corresponding author}

Sheau-Fen Yap, Senior Lecturer, Department of Marketing, Advertising, Retailing and Sales, Faculty of Business and Law, Auckland University of Technology, 46 Wakefield Street, Auckland 1010, New Zealand. Tel: +64 99219999 (ext: 5800), Fax: +64 9921 9629, Mobile: +64 2102295900 (Email: crystal.yap@aut.ac.nz) - Corresponding author

\section{Author 2}

Md. Nor Othman, Professor of Marketing, Department of Marketing, Faculty of Business and Accountancy, University of Malaya, 50603 Kuala Lumpur, Malaysia, Tel : +603-7967-3800 Fax: +603-79673980 (Email: mohdnor@um.edu.my).

\section{Author 3}

Yu-Ghee Wee, Senior Lecturer, Faculty of Entrepreneurship and Business, University Malaysia Kelantan (UMK), Karung Berkunci 36, Pengkalan Chepa, 16100 Kota Bharu, Kelantan, Malaysia. Tel: +6012-9370616 / 09-7717263, Fax: 09-7717252 (Email: yughee@umk.edu.my). 


\title{
Comparing Theories to Explain Exercise Behaviour: A Socio-Cognitive Approach
}

\begin{abstract}
Consumer education plays an important role in cultivating the beliefs that exercise helps to improve one's health status. In this vein, a solid theoretical model that provides insight into what motivates exercise participation is essential for managerial formulation of health intervention strategies. Addressing the calls for more solid theoretical work to explain exercise behaviour, this study test and compare empirically the predictive validity of three social cognitive theories the theory of reasoned action (TRA) and planned behaviour (TPB) and the modified TPB (with an additional path from subjective norms to attitude) - in predicting exercise intention. Crosssectional data was collected via self-administered surveys from a sample of adults in Malaysia. All three alternative models have achieved acceptable model fit to the data, and the TPB appeared to be a more superior to the alternative models. Given strong support for the secondorder TPB's application to exercise that is provided by our study, it seems feasible that desirable modifications in social cognitions especially the attitudinal components might lead to corresponding changes in the subjects' exercise intention. This study sets the ground for health professional, social marketers, and government to improve their understanding of exercise behaviour and, in turn, consumer welfare.
\end{abstract}

Keywords: Social cognition, theory of planned behaviour, exercise, health promotion, public health

Word count: 3446 words (including abstract) 


\section{Comparing Theories to Explain Exercise Behaviour: A Socio-Cognitive Approach}

\section{INTRODUCTION}

A healthy lifestyle that promotes physical activity is regarded as a key factor in chronic disease prevention (Bolton, Reed, Volpp and Armstrong, 2008). However, the levels of physical inactivity are increasing worldwide, from developing nations to the industrialised society (Bond and Batey, 2005). Consumer education plays an important role in cultivating the beliefs that exercise helps to improve one's health status (Thomson, 2000). In this vein, social marketing which uses commercial marketing strategies can play an important role in health behavioural change (Spotswood and Tapp, 2010). However, a solid theoretical model is needed to explain exercise and physical activity before adequate intervention efforts can be developed (Thomson, 2000).

Social cognitive models are useful to ground research in the area of health research. The influential social cognitive model frequently used to explain health behaviour is the theory of reasoned action (TRA; Ajzen and Fishbein, 1980) and theory of planned behaviour (TPB; Ajzen, 1991). Although the TPB has demonstrated impactful utility in health behavioural research, other considerations appear noteworthy. Firstly, past exercise research built around the TPB have weaknesses for their reliance on convenience and homogeneous groups such as patients (Rhodes and Courneya, 2003), adult women (Goodwin and Hill, 1999), children (Oliver, Schluter,

Schofield and Paterson, 2011) and mainly student-based samples (Hoyt, Rhodes, Hausenblas and Giacobbi, 2009). 
Secondly, the existing exercise studies have typically extended the TPB by adding one or more predictors, for example, social support, past behaviour, and social identity to improve the theory predictability and have focused on the relationship between key model constructs (Armitage and Conner, 2001). These studies have demonstrated that their extended model is adequate for explaining exercise behaviour; however, alternative models with different hypothetical structural relationships should be further explored (Byrne, 2001). Thirdly, several scholars have attempted to compare the explanatory power of TRA and TPB in context such as knowledge sharing (Ryu, Ho and Han, 2003), online grocery purchase (Hansen, Jensen and Solgaard, 2004), and e-commerce adoption (Grandon, Nasco and Mykytyn, 2011). However, it is unclear whether these findings apply to exercise context.

Reflecting the calls for more precise theoretical work to explain exercise behaviour and physical activity (Sallis, 2001), this study seeks to: (a) test and compare systematically the predictive validity of the second-order TPB and TRA in predicting exercise intention; (b) investigate whether or not the second-order structure of attitude, subjective norms and PBC can help predict one's exercise intention; and (c) test the predictive validity of the modified TPB model (with the inclusion of a path from subjective norms to attitude) as compared to TPB. Most research on exercise is dominated by studies undertaken in Western countries. Drawing on a socio-cognitive theory, this research aims at addressing research issues in an eastern culture where recent developments of the TPB/TRA have been limited. Ultimately, we hope to determine an effective framework that can potentially aid health professional, government, and other policy agencies to persuade people to engage in exercise.

Several behavioural change models such as the health belief model, protection motivation theory, theory of reasoned action and planned behaviour, self-efficacy theory, self-determination 
theory, transtheoretical model of stages of change have been popularly examined. Notably, Ajzen's TRA/TPB represents one of the leading theoretical models that have offered the basis for successful health behavioural change campaigns (Armitage and Christian, 2003).

The TPB stems from the TRA with the addition of perceived behavioural control (PBC) which aimed to improve the predictive capabilities of TRA, particularly for explaining behaviours that are not under one's volitional control (Fishbein and Ajzen, 1975). The TPB model posits that behavioural intention is the immediate antecedent of actual behaviour (Ajzen, 1991). The TPB model posits that behavioural intention, which reflects the amount of effort a person exerts to engage in a given behaviour, is the immediate determinant of that behaviour (Armitage and Conner, 1999). Intention is, in turn, determined independently by attitude, subjective norms, and PBC. While attitude and subjective norms are theorised to exert their effects upon behaviour through intentions, PBC is hypothesised to have both direct and indirect (through intention) influence on behaviour (Ajzen, 1991).

We acknowledge that empirical evidence (e.g., Godin and Kok, 1996; Hausenblas, Carron and Mack, 1997) does exist to support the addition of PBC to the TRA model. Nevertheless, these studies are either meta-analyses or empirical research to support the inclusion of the PBC construct based merely on the predictive power (i.e., R-square value). A more robust statistical technique is therefore needed to rigorously test the relative superiority of TPB over the TRA model.

More recent research relating to the model efficacy issue of TPB and TRA has adopted a competing model strategy using the structural equation modelling technique. For instance, based on the data collected from 286 physicians practicing in 13 tertiary hospitals in Korea, Ryu, Ho and Han (2003) found support for the superiority of TPB over TRA. In a study of online grocery 
buying intention, Hansen, Jensen, and Solgaard (2004) demonstrate that the TPB had achieved only a slight improvement in model fit among Danish and Swedish consumers. Following a similar line of inquiry, Grandon, Nasco, and Mykytyn (2011) failed to demonstrate significant differences between TPB and TRA among 210 managers/owners in Chile in the prediction of ecommerce adoption intention. However, it is relatively unknown whether these results apply to the exercise context. These mixed findings also suggest that sustained research on the topic may be needed to understand the predictive validity of the two theories.

One stream of exercise research has provided empirical support for a more complex factor structure of the TPB predictors. That is, the TPB predictors should comprise of two specific sub-components as opposed to the traditional single-concept (Hagger and Chatzisarantis, 2005). Specifically, attitude is theorised to be composed of affective (e.g., the enjoyment or pleasure associated with exercising) and instrumental attitude (e.g., the perceived benefits resulting from exercising). Subjective norms is hypothesised to comprise both the originally measured injunctive component (e.g., the perception of whether people in one' social network want them to exercise) and a descriptive component (e.g., whether one’s social network engage in regular exercise). Similarly, factor analysis of PBC demonstrated measurement distinctiveness between perceived control (e.g., subjects’ means and resources to exert control over exercising) and self-efficacy (e.g., subjects' capability and self confidence in exercising) (Rhodes and Courneya, 2003). Although this multidimensional TPB structure has achieved confirmatory support; however, the relative predictive validity of the second-order TPB structure versus TRA could be questioned. Our study advances the theory yet in another way by comparing the relative superiority of the second-order TPB over the second-order TRA structure. 
Miniard and Cohen (1979) argue that the conceptual and measurement distinctions between attitude and subjective norms should be explicitly addressed. Although Fishbein and Ajzen (1975) acknowledge that attitudinal and normative influences might be related to each other, they insist on the separation of attitudes and subjective norms as they could exert different influences on different types of behaviours. Choo, Chung and Pysarchik (2004) found that subjective norms had a positive effect on Indian consumers' attitudes toward processed foods. Similarly, Hansen, Jensen and Solgaard (2004) also support the inclusion of a path from subjective norms to attitude in their online grocery study. Based on these empirical evidences, the present study proposes a modified version of TPB by including an additional path from subjective norms to attitude.

In summary, this study compares and empirically tests three alternative models: TRA (Model 1), TPB (Model 2), and a modified TPB model that include an additional path from subjective norms to attitude (Model 3) to determine the model that best fit the empirical data in explaining exercise intention (see Figure 1).

\section{METHOD}

This study was conducted in Malaysia using a cross-sectional survey approach. The research instrument was a questionnaire translated from English into the Malay and Chinese Languages using back-to-back translation methods. All items were adapted from previously published work with proven psychometric quality and were assessed on a 7-point Likert-type scale. Items measuring attitude and PBC sub-components were adapted from Hagger and Chatzisarantis (2005) and Rhodes and Courneya (2003) whereas items measuring subjective norms sub- 
components and exercise intention were taken from Hagger and Chatzisarantis (2005). The questionnaires were pre-tested on 40 adults (i.e. Faculty members, undergraduate and postgraduate students) to improve its consistency, readability and clarity. Several modifications were made in terms of the wording, presentation and structure of the questionnaire. Respondents who had participated in the pre-tests were not included in the main study.

Participants for the present study were adults aged above 18 years who reported performing exercise activities at least once a week during leisure time for at least 15 minutes in duration each time for the last 3 months. Quota sampling (based on gender and ethnicity) was employed to ensure proportionate inclusion of various subgroups in the sample. Based on the composition of the total population of Malaysia, the study set a 50-50 quota for gender, 50-30-20 quota for ethnic groups (Malay, Chinese, and Indian). Quota sampling is deemed appropriate since this study aims at deriving theoretical generalisability of the integrated model as opposed to population generalisability (Calder, Philips and Tybout, 1982). A total of 512 usable responses made up the final sample size.

Data were collected using personally administered questionnaires with the assistance of student helpers recruited from several colleges and universities. A briefing on the research purposes, objectives, and procedures was provided to student helpers prior to data collection. Student helpers were trained and instructed to approach respondents (peers, neighbours, and relatives recruited through their informal contact) from different age and socio-economic groups so that data collected were not skewed towards a particular group. One lecturer from each college or university was appointed to facilitate the data collection process. 
Structural equation modelling with maximum likelihood estimation was employed in this study. A two-step approach was adopted for measurement scale validation and structural analysis (Anderson and Gerbing, 1988).

\section{RESULTS}

Of the 1,200 questionnaires distributed, 594 responses were returned for a response rate of 49.5\%. Of these returns, a total of 512 completed questionnaires were usable. Based on Armstrong and Overton's (1977) procedures, the chi-square tests showed an absence of significant differences between early and late respondents in terms of gender, age, ethnicity, and religion. We therefore conclude that non-response bias was unlikely to be an issue in our study. The demographic characteristics of the overall sample were well spread over gender groups. The majority of respondents (49\%) were aged between 20 to 29 years old. Approximately 51\% of the respondents were Malay, followed by Chinese (29\%) and Indian (15\%), reflecting the urban Malaysian population.

All three second-order TPB predictors and exercise intention scales were tested simultaneously in a single CFA model. An analysis of the priori measurement model resulted in satisfactory model fit $\left(\chi^{2}=796.74, \chi^{2} / \mathrm{df}=2.027, \mathrm{TLI}=0.951, \mathrm{CFI}=0.956, \mathrm{RMSEA}=0.045\right)$ after several modifications based on standardised residuals, modification indices and the standardised loading estimates. The hypothesised second-order measurement structures of attitude, subjective norms and PBC were supported, as loadings for its dimensions were all statistically significant $(\mathrm{p}<.001)$. 
The assessment of psychometric properties of the scales is presented in Table 1. Each factor loading of the reflective indicators was significant at 0.001 level, and all loadings exceeded the recommended level of 0.50 (Anderson and Gerbing, 1988). Generally, a composite reliability of at least 0.60 (Bagozzi and $\mathrm{Yi}, 1988$ ) and a minimum average variance extracted (AVE) of 0.50 (Fornell and Larcker, 1981) are considered acceptable. This requirement is met for all scales used in the study. As for discriminant validity, all scales for the specified model had reliabilities in excess of the correlations between them, indicating that each pair of constructs was distinct (Gaski and Nevin, 1985). Taken together, these results support both the convergent and discriminant validity of the data.

The alternative models presented in Figure 1 were translated into a structural model based on the tenet of TRA/TPB. Next, the structural equation paths for the three competing models were estimated and compared using competing model strategy. The nested-model comparison was adopted to determine which structural equation model best explains the sample covariance (Hair, Black, Babin and Anderson, 2010). The TRA (Model 1) is nested within the TPB (Model 2) by setting the path to zero from PBC to exercise intention. Next, setting the path for subjective norms to attitude to zero nests the TPB within the extended model (Model 3). Chisquare difference tests were used to test the significant improvement in the model fit (Bollen, 1989).

Overall, all three models have achieved good model fit (see Table 2). The chi-square difference test revealed that the TPB (Model 2) provides a significant (i.e., $\Delta \chi^{2}=5.12, \mathrm{p}<0.05$, $\mathrm{df}=1$ ) improvement in model fit when compared to the TRA (Model 1). Contrary to our expectation, Model 3, which extends the TPB with an additional path from subjective norms to attitude, failed to demonstrate an improvement in fit as compared to Model 2. To sum up, our 
analyses suggest that the second-order TPB (Model 2) provides the best fit to the empirical data. An examination of the structural model demonstrated that the second order structure of attitude $(\beta=.789, \mathrm{p}<.001)$, subjective norms $(\beta=.122, \mathrm{p}<.05)$ and $\mathrm{PBC}(\beta=.191, \mathrm{p}<.05)$ each has a positive effect on exercise intention. Particularly strong effect of attitude on the subjects' exercise intention was observed.

In order to strengthen the cross-validation and theoretical veracity of the findings, we split the sample in two sub-groups based on the level of exercise, gender and age variables. An overall $\chi^{2}$ difference test was then assessed for each of the sub-groups based on the second-order TPB model. Model comparisons were conducted between (a) a general two-group model which allows the specified parameters to vary across groups; and (b) a model that restricts the specified paths to be equal across groups (Byrne, 2001). A significant $\chi^{2}$ difference between the constrained and unconstrained model implies that the models for the two sub-groups are dissimilar (Hair et al., 2010). As presented in Table 3, the $\Delta \chi^{2}$ for the three proposed sub-groups are consistently lower than the threshold of $7.815(\Delta \mathrm{df}=3)$, suggesting that the model fit for second-order TPB structure does that change significantly according to the variation in the level of exercise, gender and age. Overall, this finding provides some empirical evidences for the validation of the second-order TPB structure.

\section{DISCUSSION}

Understanding why people participate in exercise is an important issue for managerial formulation of strategies that attempt to address the concern for prevalent sedentary lifestyle. However, gaining long-term, effective and consistent behavioural change aimed at educating the 
public to be physically active can be a challenging task. Given strong support for the secondorder TPB's application to exercise that is provided by our study, it seems feasible that desirable modifications in social cognitions especially the attitudinal aspect might lead to corresponding changes in their exercise intention. This study sets the ground for health professional, social marketers, and government to improve their understanding of exercise behaviour and, in turn, consumer welfare. Ultimately, they could be in a better position to develop effective health intervention campaigns and educational programs.

The present study compares the predictive validity of three competing theoretical models for explaining individual exercise intention. Generally, all three alternative models have achieved acceptable model fit to the data. The finding that TPB is more superior to TRA in predicting exercise behaviour is in accordance with Biddle and Nigg's (2000) extensive review of the theories of exercise behaviour which concludes that TPB is one of the most comprehensive and validated theories for explaining exercise behaviour. The cross validation analyses also further strengthen the theoretical veracity of the findings and provide empirical evidences for the validation of the second-order TPB structure. Given this strong empirical support, the present second-order TPB structure can serve as a springboard for future research to examine other health behaviour such as weight control, tobacco use, healthy eating, sunscreen use and stress management.

The results for the overall sample provide general support for the fact that the secondorder structure of attitudes, subjective norms, and PBC positively predicted exercise intention. The finding about attitude being a significant predictor of exercise intention makes theoretical sense as the more favourable the perception in one's attitude toward participating in exercise activities, the greater likelihood that the person will participate in exercise activities. Among the 
TPB predictors, attitude exerts the strongest effect on exercise intention. This finding reflect the notion that attitude formation and change has been an important concept in the fields of economies, psychology, social psychology, and marketing (Lindgren and Konopa, 1980). Indeed, the attitude construct is regarded as the core predictor of numerous behaviours and behavioural intention (see Armitage and Conner, 2001). It appears that emphasis on the attitudinal components could be an effective way to encourage people to exercise. For instance, affectivebased interventions that involve creating positive experiences (e.g., excitement and enjoyment) associated with exercise couple with emphasis on the persuasion through factual information (e.g., benefits of exercise) are likely to yield successful results.

Past exercise studies have thus far demonstrated the predictive role of subjective norms to be weak or insignificant (Brickell, Chatzisarantis and Pretty 2006; Rhodes, Blanchard and Matheson 2006). As such, some exercise researchers divert their attention to other social construct such as social provision and family support (Saunders, Motl, Dowda, Dishman and Pate 2004). Contrary to these past studies, our finding suggests that subjective norms had a significant effect (though relatively smaller compared to attitude and PBC) on exercise intention. One possible reason for this contradictory result could be due to the second-order structure of the subjective norms measurement.

The finding that PBC predicted exercise intention and the present empirical evidence for the superiority of TPB over TRA further support the importance of PBC construct. This finding also indicates that exercise decision is not under a person's full volitional control. Future research should examine beyond the attitude and subjective norms but to explore the control factor that possibly influence individual's exercise behaviour such as physical inability, time constraint, neighbourhood security, availability of the exercise equipment and so on. 
Limitations of this study should be considered when interpreting the results of this study. A cross-sectional design can magnify the effect size of findings as all measures are completed at the same time. Also, potential social desirability may have artificially inflated the observed relationship when self-report measures are adopted. Nevertheless, most of the TPB research utilise cross-sectional study designs (see Godin and Kok, 1996) and have relied largely on selfreport data, and the potential of such biases to invalidate the model seems to be overstated (Ajzen and Fishbein, 2004). Lastly, there are also concerns regarding sample generalisability. The final sample consists of relatively larger number of young participants. Although the social cognitive predictors contained in the TPB are relatively invariant to age (Hagger, Chatzisarantis and Biddle, 2002), and careful consideration has been given in the quota set, the generalisability of the findings to a wider population should be done with caution.

\section{CONCLUSION}

Future research should replicate the results in other behavioural domains using a longitudinal approach to cross validate the second-order TPB model and compare it with other specified theories. More objective measures such as fitness class attendance or activity monitoring should be considered.

\section{References}

Ajzen, I., 1991. The theory of planned behavior. Organizational Behavior and Human Decision Processes, 50 (2), 179-212.

Ajzen, I. and Fishbein, M., 1980. Understanding attitudes and predicting social behavior. Englewood Cliffs, NJ: Prentice Hall. 
Ajzen, I. and Fishbein, M., 2004. The Influence of Attitudes on Behavior. In Handbook of Attitudes and Attitude Change: Basic Principles. D. Albarracín, B. T. Johnson and M. P. Zanna (Eds.). Mahwah. NJ: Erlbaum, 173-221.

Anderson, J. C. and Gerbing, D. W., 1988. Structural equation modeling in practice: A review and recommend two-step approach. Psychological Bulletin, 103 (3), 411-423.

Armitage, C. J. and Christian, J., 2003. From attitudes to behavior: Basic and applied research on the theory of planned behavior. Current Psychology: Developmental, Learning, Personality, Social, 22, 187-195.

Armitage, C. J. and Conner, M., 1999. The theory of planned behavior: Assessment of predictive validity and perceived control. The British Journal of Social Psychology, 38 (1), 35-54.

Armitage, C. J. and Conner, M., 2001. Efficacy of the theory of planned behavior: A metaanalytic review. The British Journal of Social Psychology, 40 (4), 471-499.

Bagozzi, R. P. and Yi, Y., 1988. On the evaluation of structural equation models. Journal of the Academy of Marketing Science, 16, 74-94.

Biddle, S. J. H. and Nigg, C. R., 2000. Theories of exercise behavior. International Journal of Sport Psychology, 31 (2), 290-304.

Bollen, K. A., 1990. Overall fit in covariance structural models: Two types of sample size effects. Psychological Bulletin, 107 (2), 256-259.

Bolton, L. E., Reed, A., Volpp, K. G. and Armstrong, K., 2008. How does drug and supplement marketing affect a healthy lifestyle?. Journal of Consumer Research, 34, 713-726.

Bond, K. A. and Batey, J., 2005. Running for their lives: A qualitative analysis of the exercise experience of female recreational runners. Women in Sport and Physical Activity Journal, 14 (2), 69-782.

Brickell, T. A., Chatzisarantis, N. L. D. and Pretty, G. M., 2006. Using past behavior and spontaneous implementation intentions to enhance the utility of the theory of planned behavior in predicting exercise. British Journal of Health Psychology, 11 (2), 249-262.

Byrne, B. M., 2001. Structural Equation Modeling with AMOS: Basic Concepts, Applications, and Programming, London: Lawrence Erlbaum Associates.

Calder, B. J., Philips, L. W. and Tybout, A. M., 1982. The concept of external validity. Journal of Consumer Research, 9, 240-244.

Choo, H. J., Chung, J. E. and Pysarchik, D. T., 2004. Antecedents to new food product purchasing behavior among innovator groups in India. European Journal of Marketing, 38 (5/6), 608-625. 
Fishbein, M. and Ajzen, I., 1975. Belief, Attitude, Intentions and Behavior: An Introduction to Theory and Research, Reading, MA: Addison-Wesley.

Fornell, C. and Larcker, D. F., 1981. Evaluating structural equations with unobservable variables and measurement error. Journal of Marketing Research, 18 (1), 39-50.

Gaski, J. F. and Nevin, J. R., 1985. The differential effects of exercised and unexercised power sources in a marketing channel. Journal of Marketing Research, 22, 130-142.

Godin, G. and Kok, G., 1996. The theory of planned behavior: A review of its applications to health-related behaviors. American Journal of Health Promotion, 11 (2), 87-98.

Goodwin, C. and Hill, R. P., 1999. Commitment to physical fitness: Commercial influences on long-term healthy consumer behaviors. Advances in Consumer Research, 26, p. 99.

Grandon, E. E., Nasco, S. A. and Mykytyn, P. P., 2011. Comparing theories to explain ecommerce adoption. Journal of Business Research, 64 (3), 292-298.

Hagger, M. S. and Chatzisarantis, N. L. D., 2005. First-and higher-order models of attitude, normative influence, and perceived behavioural control in the theory of planned behavior. British Journal of Social Psychology, 44 (4), 513-535.

Hagger, M. S., Chatzisarantis, N. L. D. and Biddle, S. J. H., 2002. A meta-analytic review of the theories of reasoned action and planned behavior in physical activity: Predictive validity and the contribution of additional variables. Journal of Sport and Exercise Psychology, 24, 3-32.

Hair, J. F., Black, W. C., Babin, B. J. and Anderson, R. E., 2010. Multivariate Data Analysis. $7^{\text {th }}$ ed. Upper Saddle River, New Jersey: Prentice Hall.

Hansen, T., Jensen, J. M. and Solgaard, H. S., 2004. Predicting online grocery buying intention: A comparison of the theory of reasoned action and the theory of planned behavior. International Journal of Information Management, 24 (6), 539-550.

Hausenblas, H. A., Carron, A. V. and Mack, D. E., 1997. Application of the theories of reasoned action and planned behavior to exercise behavior: A Meta-analysis. Journal of Sport and Exercise Psychology, 19 (1), 36-51.

Hoyt, A. L., Rhodes, R. E., Hausenblas, H. A. and Giacobbi, P. R., 2009. Integrating five-factor model facet-level traits with the theory of planned behavior and exercise', Psychology of Sport and Exercise, 10, 565-572.

Lindgren, J. H. and Konopa, L. J., 1980. A comparative analysis of multiattribute attitude models, Journal of the Academy of Marketing Science, 8 (4), 374-389. 
Miniard, P. W. and Cohen J. B., 1979. Isolating attitudinal and normative influences in behavioral intentions models. Journal of Marketing Research, XVI, 102-110.

Oliver, M., Schluter, P. J., Schofield, G. M. and Paterson, J., 2011. Factors related to accelerometer-derived physical activity in Pacific children aged 6 years. Asia Pacific Journal of Public Health, 23, 44-56.

Rhodes, R. E., Blanchard, C. M. and Matheson, D. H., 2006. A multicomponent model of the theory of planned behavior. British Journal of Health Psychology, 11 (1), 119-137.

Rhodes, R. E. and Courneya, K. S., 2003. Investigating multiple components of attitude, subjective norm, and perceived control: An examination of the theory of planned behavior in the exercise domain. British Journal of Social Psychology, 42, 129-146.

Ryu, S., Ho, S. H. and Han, I., 2003. Knowledge sharing behavior of physicians in hospitals. Expert Systems with Applications, 25 (1), 113-122.

Sallis, J. F., 2001. Progress in behavioral research on physical activity. Annals of Behavioral Medicine, 23, 77-78.

Saunders, R. P., Motl, R. W., Dowda, M., Dishman, R. K. and Pate, R. R., 2004. Comparison of social variables for understanding physical activity in adolescent girls. American Journal of Health Behavior, 28 (5), 426-436.

Spotswood, F. and Tapp, A., 2010. Socio cultural change - the key to social marketing success? A case study of increasing exercise in working class communities. International Journal of Health Promotion and Education, 48 (2), 52-57.

Symons Downs, D., Graham, G. M., Yang, S., Bargainier, S. and Vasil, J., 2006. Youth exercise intention and past exercise behavior: Examining the moderating influences of sex and meeting exercise recommendations. Research Quarterly for Exercise and Sport, 77 (1), 91-99.

Thomson, P., 2000. Exercise and health: A review of the usefulness of behavioural change theories in helping patients to become habitually active. International Journal of Health Promotion and Education, 38 (1), 10-18.

USDHHS, 2004. USDHHS Physical Activity Guidelines. United States Department of Health and Human Services. Retrieved December 12, 2008, from http://www.hhs.gov/. 
Table 1. Confirmatory factor analysis for convergent validity

\begin{tabular}{|l|c|c|c|c|}
\hline \multicolumn{1}{|c|}{ Construct } & $\begin{array}{c}\text { No. of } \\
\text { Items }\end{array}$ & Item Loadings & $\begin{array}{c}\text { Construct } \\
\text { Reliability }\end{array}$ & AVE \\
\hline Attitude Components (second-order construct) \\
\hline Instrumental attitude & 5 & $0.593-0.802^{* *}$ & 0.848 & 0.530 \\
\hline Affective attitude & 5 & $0.516-0.841^{* *}$ & 0.867 & 0.571 \\
\hline Subjective norm Components (second-order construct) & 0.533 \\
\hline Injunctive Norm & 3 & $0.667-0.766^{* *}$ & 0.773 & 0.756 \\
\hline Descriptive Norm & 3 & $0.839-0.926^{* *}$ & 0.903 & \\
\hline PBC Components (second-order construct) \\
\hline Perceived Control & 4 & $0.624-0.905^{* *}$ & 0.861 & 0.613 \\
\hline Self-efficacy & 4 & $0.641-0.868^{* *}$ & 0.840 & 0.573 \\
\hline Exercise Intention & 6 & $0.788-0.814^{* *}$ & 0.900 & 0.601 \\
\hline
\end{tabular}

$* * \mathrm{p}<.001$ 
Table 2. Overall fit indices of the alternative models

\begin{tabular}{lllccc}
\hline Fit index & & $\begin{array}{l}\text { Recommended cut- } \\
\text { off value }\end{array}$ & $\begin{array}{c}\text { TRA } \\
\text { (Model 1) }\end{array}$ & $\begin{array}{c}\text { TPB } \\
\text { (Model 2) }\end{array}$ & $\begin{array}{c}\text { Modified TPB } \\
\text { (Model 3) }\end{array}$ \\
\hline Absolute fit & $\chi^{2}$ & Near to d.f. & 801.86 & 796.74 & 823.60 \\
measures & d.f. & - & 394 & 393 & 394 \\
& $\chi^{2} / \mathrm{df}$ & $\leq 3.0$ & 2.035 & 2.027 & 2.09 \\
& GFI & $\geq 0.90$ & .902 & .903 & .901 \\
& RMSEA & $\leq 0.08$ & .045 & .045 & .046 \\
\hline Incremental & TLI & $\geq 0.90$ & .951 & .951 & .948 \\
fit measures & CFI & $\geq 0.90$ & .955 & .956 & .953 \\
\hline
\end{tabular}


Table 3. Cross validation results

\begin{tabular}{|l|c|c|c|c|c|c|c|c|}
\hline \multicolumn{1}{|c|}{ Model } & $\chi^{\mathbf{2}}$ & $\boldsymbol{\chi}^{\mathbf{2} / \mathbf{d f}}$ & TLI & CFI & RMSEA & $\Delta \boldsymbol{\chi}^{\mathbf{2}}$ & $\Delta$ df & Threshold \\
\hline High vs. Low Active $^{\mathbf{a}}$ & & & & & & & & \\
Unconstraint & 1364.64 & 1.736 & 0.914 & 0.922 & 0.038 & 6.57 & 3 & 7.815 \\
Constraint & 1371.21 & 1.738 & 0.914 & 0.922 & 0.038 & & & \\
\hline Male vs. Female samples & & & & & & & & \\
Unconstraint & 1316.98 & 1.676 & 0.937 & 0.943 & 0.036 & 7.05 & \multirow{2}{*}{3} & 7.815 \\
Constraint & 1324.03 & 1.678 & 0.936 & 0.942 & 0.036 & & & \\
\hline Young vs. Mature samples & & & & & & & & \\
Unconstraint & 1321.55 & 1.681 & 0.933 & 0.939 & 0.038 & 7.49 & 3 & 7.815 \\
Constraint & 1329.04 & 1.684 & 0.933 & 0.939 & 0.038 & \\
\hline
\end{tabular}

Note: ${ }^{a}$ Based on the recommendation of Symons Downs et al. (2006), respondents who meet the exercise recommendations (i.e. 4 or more times per week) are classified as 'high active' exerciser; respondents who did not meet the recommendations (i.e. 3 or less times per week) are categorised as 'low active' exerciser. Health experts have agreed that this exercise group classification is appropriate and congruent with the international guidelines for physical activity (USDHHS 2004). 


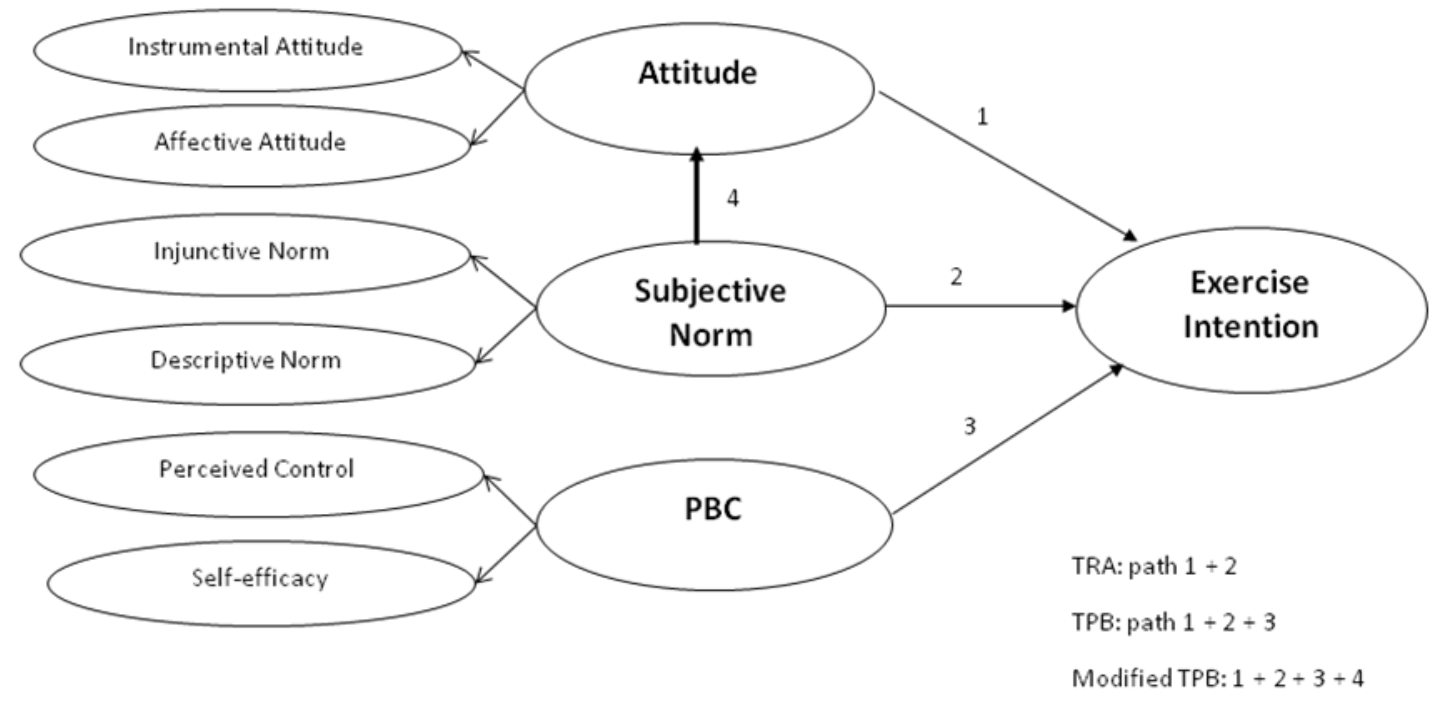

Figure 1. Investigated Research Model 